\title{
Vitamin D Deficiency in Patients with Diabetic Peripheral Neuropathy
}

\author{
Hameedullah Khan', Ihsanullah Rajar ${ }^{2}$, Abdul Rauf Memon ${ }^{3}$, Nadeem Naeem ${ }^{4}$ \\ ${ }^{1}$ Assistant professor, Neuro surgery Department of Indus Medical College Tando Muhammad khan \\ 2 Senior Registrar, Department of Medicine, LUMHS, Nawabshah \\ ${ }^{3}$ Senior Registrar, Department of Neurosurgery, LUMHS, Nawabshah \\ ${ }^{4}$ Fellow, Diabetes, Endocrinology and Metabolism, Baqai Institute of Diabetology and Endocrinology Karachi
}

\section{ABSTRACT}

Objective: To determine the frequency of vitamin $D$ deficiency in patients presenting with diabetic peripheral neuropathy Patients and Methods: This cross sectional study was carried out in Department of Medicine and Neurology Indus Medical College, Tando Muhammad khan. from March 2017 to August 2017. Total 74 cases of Diabetes Mellitus presenting with peripheral diabetic neuropathy were selected for the study. Evolution of degree of Neuropathy was based on TCSS score as: \{no neuropathy: $\leq 5$, severe: $\geq 12$, moderate: $9-11$ and mild: $6-8\}$. Vitamin $D$ level was categorized as (deficiency $(0-20 \mathrm{ng} / \mathrm{ml})$, insufficiency $(21-30 \mathrm{ng} / \mathrm{ml})$ sufficiency $(>30 \mathrm{ng} / \mathrm{ml})$, excess $(>50 \mathrm{ng} / \mathrm{ml})$ and toxicity $(>100 \mathrm{ng} / \mathrm{ml})$. All the data was entered in SPSS.

Results: Total 74 patients with diabetic neuropathy were studied. Vast majority of patients $36(48.6 \%)$ were found in age group 51-60 years, Majority were males $45(60.8 \%)$. Most of the cases $35(47.3 \%)$ were with 1-3 years duration of neuropathy. Majority of patients $42(56.8 \%)$ were found with Mild peripheral neuropathy. Vitamin-D deficiency was present in 2(43.2\%) cases and insufficiency was observed in $27(36.5 \%)$ cases. No significant association was found between vitamin $\mathrm{D}$ deficiency and severity of neuropathy.

Conclusion: Vitamin D deficiency was found (43.2\%) in patients of diabetic peripheral neuropathy. Vitamin screening and intake of supplement is necessary, will help to decrease the complication of peripheral neuropathy in Diabetic cases.

Key words: Diabetes, Peripheral neuropathy, Vitamin D

Author's Contribution

${ }^{1}$ Conception, synthesis, planning of research

and manuscript writing Interpretation and

discussion

2,3 Data analysis, interpretation and

manuscript writing, ${ }^{4}$ Active participation in

data collection.

Cite this article. Khan H, Rajar I, Memon AR, NaeemN. Vitamin-D Deficiency in Patients with

diabetic Peripheral Neuropathy. JIMDC.2018; 7(4):291-294

$\begin{array}{ll}\text { Address of Correspondence } & \text { Article info. } \\ \text { Hamidullah Khan } & \text { Received: June 13, 2018 } \\ \text { Email: dr.2581hameedkhan @gmail.com } & \text { Accepted: August 16, 2018 }\end{array}$

Accepted: August 16, 2018

\section{Introduction}

Diabetes Mellitus Type 2 is a chronic metabolic syndrome characterized by abnormal blood glucose levels. About 170 million people are affected with type 2 diabetes globally and the figures will increase to 370 million in 2030 and 642 million in 2040.1,2 As per a Pakistani survey, incidence of currently diagnosed diabetes was $6.8 \%$ in females and $5.1 \%$ in males. ${ }^{3}$ Neuropathy is a commonest complication of diabetes mellitus and diabetes is the commonest factor of neuropathy in the United States, affecting around $50 \%$ of cases with Diabetes Mellitus. Symptoms generally involve weakness, pain, tingling, and numbness. ${ }^{4,5}$ Diabetic peripheral neuropathy is a frequent problem that affects these patients and is a key factor of elevated mortality as well as morbidity. ${ }^{6}$ Diabetic neuropathy is much challenging problem of diabetes, correlated with vast economic burden. It is reported to 


\begin{tabular}{|l|c|c|}
\hline \multicolumn{3}{|c|}{ Table 1: Demographic characteristics of patients } \\
(n=74) \\
\hline \multicolumn{1}{|c|}{ Basic characteristic } & Frequency & Percentage \\
\hline Age groups (years) & & \\
\hline $40-50$ & 27 & 36.5 \\
\hline $51-60$ & 36 & 48.6 \\
\hline$>60$ & 11 & 14.9 \\
\hline Total & 74 & 100.0 \\
\hline Gender & & \\
\hline Female & 29 & 39.2 \\
\hline Male & 45 & 60.8 \\
\hline Total & 74 & 100.0 \\
\hline Duration of neuropathy & & \\
(years) & & \\
\hline $1-3$ & 35 & 47.3 \\
\hline $4-5$ & 24 & 32.4 \\
\hline$>5$ & 15 & 20.3 \\
\hline Total & 74 & 100.0 \\
\hline Peripheral neuropathy & & \\
\hline Mild & 42 & 56.8 \\
\hline Moderate & 24 & 32.4 \\
\hline Severe & 8 & 10.8 \\
\hline Total & 74 & 100.0 \\
\hline & & \\
\hline
\end{tabular}

have an incidence of $39.6 \%$ within Karachi. ${ }^{7}$ It is essential to explain the potential risk factors for Diabetic peripheral neuropathy. As widely accepted, Diabetic peripheral neuropathy is raised with age and duration of diabetes. Current studies suggest that level of vitamin $D$ contributes tremendously in influencing the generation as well as progression of diabetes mellitus in addition to complications related to it. ${ }^{8}$ Vitamin $D$ is a vital fat-soluble vitamin, which is strongly associated with human health. Deficiency of Vitamin D can lead to several health complications for example distinguished osteoporosis during adulthood. ${ }^{9}$

Numerous articles reported that vitamin D can possibly contribute its therapeutic role remarkably through immuno-modulatory mechanism. In addition, Vitamin D contributes significantly in preserving pancreatic $\beta$-cell functions by affecting several channels. Several studies have highlighted the potential relationship of diabetic peripheral neuropathy and deficiency of vitamin $D . .^{10-13} \mathrm{In}$ the meantime, Therefore, deficiency of vitamin $D$ can lead to the diabetes risk and its complications involving neuropathy, however because of the study design

\begin{tabular}{|l|c|}
\hline \multicolumn{2}{|c|}{$\begin{array}{c}\text { Table 2: Levels of vitamin } \mathbf{D} \text { in studied population } \\
(\mathbf{n}=\mathbf{7 4})\end{array}$} \\
\hline \multicolumn{1}{|c|}{ Presentation } & Frequency (\%) \\
\hline Levels of vitamin D (ng/ml) & \\
\hline Deficiency (0-20) & $32(43.2)$ \\
\hline Insufficiency (21-30) & $27(36.5)$ \\
\hline Sufficiency (>30) & $12(16.2)$ \\
\hline Excess $(>50)$ & $03(04.1)$ \\
\hline
\end{tabular}

difference, small sample size, regions and population of studies, there is yet no evident conclusion regarding the relationship amid diabetic peripheral neuropathy and vitamin D within diabetic cases. Currently in a study carried out, meta-analysis and systematic review to discover the effect of vitamin $D$ levels in the diabetic peripheral neuropathy development within Type II diabetic mellitus, concluded that deficiency of vitamin $D$ are 1.22 folds to be influenced by DPN contrasted to normal vitamin $D$ levels within Asian and suggested more research on this event. ${ }^{14}$ Therefore this study has been planned to evaluate the deficiency of vitamin $D$ in diabetic peripheral neuropathy patients in our population.

\section{Patients and Methods}

This cross sectional study was carried out in Department of Medicine and Neurology at Indus Medical College Tando Muhammad khan. Study duration was 6 months from March 2017 to August 2017. Total 74 cases of diabetes mellitus presenting with peripheral diabetic neuropathy were selected for the study. Sample size was calculated by raosoft software by taking proportion of diabetic peripheral neuropathy $36.6 \%$ with $10 \%$ margin of error and $95 \%$ confidence level. ${ }^{21}$

Neuropathy degrees were based on Toronto Clinical Scoring System (TCSS) score applied within an earlier study as, no neuropathy: $\leq 5$, mild:6-8, moderate: 9-11, severe: $\geq 12 .^{15}$ Complete medical history including duration of diabetes, duration of neuropathy and clinical examination were carried out. Patients with history of smoking, alcohol, obesity, anemia and uncontrolled hypertension were excluded. Total $5 \mathrm{cc}$ intravenous blood sample was taken to analyze vitamin D levels. Vitamin D level was categorized as, Deficiency: 0-20 ng/ml, Insufficiency: 21-30 ng/ml, Sufficiency: $>30 \mathrm{ng} / \mathrm{ml}$, Excess: $>50 \mathrm{ng} / \mathrm{ml}$ and Toxicity: $>100 \mathrm{ng} / \mathrm{ml}$. All the data 


\begin{tabular}{|l|c|c|c|c|c|}
\hline \multicolumn{5}{|c|}{ Table 3: Degree of peripheral neuropathy according to Vitamin D levels } \\
\hline \multirow{2}{*}{ Vitamin D level (ng/ml) } & & \multicolumn{4}{c|}{ Neuropathy } \\
\cline { 2 - 5 } & Mild n(\%) & Moderate $\mathrm{n}(\%)$ & Severe $\mathrm{n}(\%)$ & Total & $\mathrm{p}$-value \\
\hline Deficiency (0-20) & $17(53)$ & $12(38)$ & $03(09)$ & 32 & \\
\hline Insufficiency (21-30) & $13(48)$ & $10(37)$ & $04(15)$ & 27 & \multirow{2}{*}{0.507} \\
\hline Sufficiency (>30) & $09(75)$ & $02(17)$ & $01(08)$ & 12 & \\
\hline Excess (>50) & $03(100)$ & $00(00)$ & $00(00)$ & 03 & \\
\hline
\end{tabular}

were entered on predesigned proforma. SPSS was used for data analysis, frequency and percentage were computed for qualitative variable. Mean and standard deviation were computed for quantitative variable. Chisquare test was applied to assess the association of vitamin $D$ level with severity of neuropathy. P-value less than 0.05 was taken as statistically significant.

\section{Results}

Total 74 patients with diabetic neuropathy were studied. Mean age of patients was $52.8 \pm 5.44$ years. Majority of patients (48.6\%) were found in age group 51-60 years. Gender wise distribution showed that males (60.8\%) were in majority. Out of total 74 , most patients (47.3\%) presented with in 1-3 years of duration of neuropathy followed by $4-5$ years (32.4\%). Majority of patients $(56.8 \%)$ were found to have mild peripheral neuropathy (Table 1). Out of overall 74 patients, Vitamin-D deficiency was found in $43.2 \%$. Excess levels of vitamin $D$ were present only in $4.1 \%$ (Table 2). Degree of peripheral neuropathy was insignificantly associated with vitamin $D$ levels. Out of 32 patients suffering from vitamin $D$ deficiency, $53 \%$ presented with mild neuropathy. In vitamin D insufficiency group, $48 \%$ had mild neuropathy. In vitamin $\mathrm{D}$ sufficiency proportion of mild neuropathy was 75\% (Table 3).

\section{Discussion}

In this study there is high frequency of vitamin $D$ deficiency in diabetic patients. Peripheral neuropathy findings of our study underline the importance of screening for vitamin $D$ deficiency in diabetic patients because vitamin $\mathrm{D}$ contributes significantly in diminishing the risk of several chronic disorders, like cancers, infections and cardiovascular diseases. ${ }^{15}$ This is particularly pertinent for diabetic patients who are at increased risk for acquiring these conditions as compared to the general population and therefore can possibly advantage from increased levels of vitamin D. ${ }^{16-18}$ There are both in vivo and in vitro evidence of Vitamin-D for being a neurotrophic substance and that it modulates neuromuscular functions as well as differentiation and neuronal growth. Peripheral neuropathy is a distressing and frequently a painful condition. Autoimmune disorders, infections, alcoholism, diabetes or trauma are potential cause. Peripheral neuropathy can cause infection or numbness in affected limb. Adequate Vitamin-D can assist in keeping the nervous system strong, and can possibly contribute in diminishing the peripheral neuropathy symptoms. In our study, out of 74 , most of the cases $35(47.3 \%)$ were with 1-3 years of duration of neuropathy, 24 cases (32.4\%) with 4-5 years and just 15 cases $(20.3 \%)$ were found with $>5$ years of duration of neuropathy. Greater part of patients $42(56.8 \%)$ were found with mild peripheral neuropathy, followed by moderate and sever, $24(32.4 \%) \& 8(10.8 \%)$, respectively. In comparison to this, study conducted by Sheikh $A$ et al 17 reported that a substantial proportion of Diabetic patients in Karachi are deficit in vitamin D.

This can possibly explain a significant relationship between the peripheral diabetic neuropathy severity and vitamin D levels, have been reported. In our study, out of total cases of diabetic peripheral neuropathy, vitamin $D$ deficiency was prevalent as $32(43.2 \%)$. In comparison to our study, Diaz VA et al ${ }^{19}$ reported in their study that, $30.7 \%$ of diabetic adults had nephropathy, $48.9 \%$ were deficit in vitamin $D$ and $36.6 \%$ had insufficiency of vitamin D. One more study of Soderstrom LH et al ${ }^{11}$ exhibited that insufficiency of Vitamin $D$ was correlated with symptoms of self-stated peripheral neuropathy. 50\% reported numbness (paresthesia) or pain within their feet 
or hands; $37 \%$ reported tingling or pain within feet or hands; and $38 \%$ reported loss of feeling or numbness in feet or hands. Another study conducted by Shehab $D$ et al also documented that deficiency of Vitamin $D$ is an independent risk factor for diabetic peripheral neuropathy. ${ }^{18}$

\section{Conclusion}

Vitamin D deficiency was seen in $43.3 \%$ in diabetic peripheral neuropathy cases, Vitamin screening and supplementation will help to decrease the complication of peripheral neuropathy in diabetic cases.

\section{References}

1. Olt $\mathrm{S}$. Relationship between vitamin $\mathrm{D}$ and glycemic control in patients with type 2 diabetes mellitus. IntJ clin ExpMed. 2015;8(10):19180

2. Saleem $S$, Siddiqui A, lqbal Z. Vitamin D Deficiency in Patients of Type 2 Diabetes. Pakistan journal of medical \& health sciences. 2017; 11(4):1324-6

3. Qidwai W, Ashfaq T. Imminent epidemic of diabetes mellitus in Pakistan: issues and challenges for health care providers. Jlumhs 2010; 9(3);112-113

4. Ishaq M, Khan GJ, ur Rahman S, Zulfiqar S. Prevalence of complications in type 2 diabetes mellitus patients. Pakistan Journal of Physiology. 2013;9 (2):35-7.

5. Argoff C.E., Cole B.E., Fishbain D.A., Irving G.A. Diabetic peripheral neuropathic pain: clinical and quality-of-life issues. Mayo Clin Proc. 2006;81(4 Suppl): S3-S11

6. Ahmed U. Prevalence of chronic complications and associated factors in type 2 diabetes. J Pak Med Assoc. 2004; 54:54-59

7. Penckofer S., Kouba J., Wallis D.E., Emanuele M.A. Vitamin $D$ and diabetes: let the sunshine. Diabetes Educ. 2008;34(6) 939-940

8. Smith TJ, Lanham-New SA, Hart KH. Vitamin D in adolescents: are current recommendations enough? The Journal of steroid biochemistry and molecular biology. 2017; 173:265-72

9. Benrashid M, Moyers K, Mohty M, Savani BN. Vitamin $D$ deficiency, autoimmunity, and graft-versushost-disease risk: implication for preventive therapy. Exp Hematol 2012;40(4):263-7
10. Bell DS. Reversal of the symptoms of diabetic neuropathy through correction of vitamin $D$ deficiency in a type 1 iabetic patient. Case Rep Endocrinol 2012;2012: Article ID:165056: 3

11. Soderstrom LH, Johnson SP, Diaz VA, Mainous AG. Association between vitamin $D$ and diabetic neuropathy in a nationally representative sample:results from 2001-2004 NHANES. Diabet Med 2012;29(1):50-5

12. Putz $Z$, Martos $T$, Németh $N$, Körei $A E$, Szabó $M$, Vági $\mathrm{OE}$, et al. Vitamin $\mathrm{D}$ and neuropathy. Orv Hetil 2013;154(51):2012-5

13. Qu GB, Wang LL, Tang $X, W u ~ W$, Sun YH. The association between vitamin $D$ level and diabetic peripheral neuropathy in patients with type 2 diabetes mellitus: An update systematic review and metaanalysis. Journal of clinical \& translational endocrinology. 2017; 9:25-31

14. Inoue M, Iwasaki M, Otani T, Sasazuki S, Noda M, Tsugane S. Diabetes mellitus and the risk of cancer: results from a large-scale population-based cohort study in Japan. Arch Intern Med 2006;166(17):18717

15. Grundy SM, Howard BS, Sidney ER Jr, Robert R, Rita Bonow RO. Prevention Conference VI: Diabetes and Cardiovascular Disease: executive summary: conference proceeding for healthcare professionals from a special writing group of the American Heart Association. Circulation 2002; 105:2231-9.

16. Bertoni AG, Sayda S, Brancati FL. Diabetes and the risk of infection- related mortality in the US. Diabetes Care 2001; 24(6):1044-9

17. Sheikh A, Saeed Z, Jafri SA, et al. Vitamin D levels in asymptomatic adults-a population survey in Karachi, Pakistan. PLoS ONE 2012; 7(3): e33452

18. Shehab D, Al-Jarallah $\mathrm{K}$, Mojiminiyi OA, et al. Does vitamin $D$ deficiency play a role in peripheral neuropathy in type 2 diabetes? Diabet Med 2012; 29(1):43-9

19. Diaz VA, Mainous AG, Carek PJ, Wessell AM, Everett CJ. The association of vitamin $D$ deficiency and insufficiency with diabetic nephropathy: implications for health disparities. The Journal of the American Board of Family Medicine. 2009 Sep 1;22(5):5217 